\title{
Brain injury in sports
}

\author{
John Lloyd, PhD, ${ }^{1,2}$ and Frank Conidi, DO, MS ${ }^{3,4}$

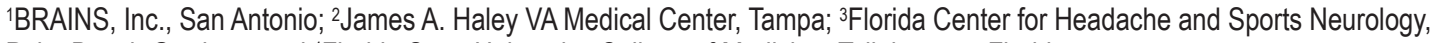 \\ Palm Beach Gardens; and ${ }^{4}$ Florida State University, College of Medicine, Tallahassee, Florida
}

\begin{abstract}
OBJECTIVE Helmets are used for sports, military, and transportation to protect against impact forces and associated injuries. The common belief among end users is that the helmet protects the whole head, including the brain. However, current consensus among biomechanists and sports neurologists indicates that helmets do not provide significant protection against concussion and brain injuries. In this paper the authors present existing scientific evidence on the mechanisms underlying traumatic head and brain injuries, along with a biomechanical evaluation of 21 current and retired football helmets.

METHODS The National Operating Committee on Standards for Athletic Equipment (NOCSAE) standard test apparatus was modified and validated for impact testing of protective headwear to include the measurement of both linear and angular kinematics. From a drop height of $2.0 \mathrm{~m}$ onto a flat steel anvil, each football helmet was impacted 5 times in the occipital area.
\end{abstract}

RESULTS Skull fracture risk was determined for each of the current varsity football helmets by calculating the percentage reduction in linear acceleration relative to a 140-g skull fracture threshold. Risk of subdural hematoma was determined by calculating the percentage reduction in angular acceleration relative to the bridging vein failure threshold, computed as a function of impact duration. Ranking the helmets according to their performance under these criteria, the authors determined that the Schutt Vengeance performed the best overall.

CONCLUSIONS The study findings demonstrated that not all football helmets provide equal or adequate protection against either focal head injuries or traumatic brain injuries. In fact, some of the most popular helmets on the field ranked among the worst. While protection is improving, none of the current or retired varsity football helmets can provide absolute protection against brain injuries, including concussions and subdural hematomas. To maximize protection against head and brain injuries for football players of all ages, the authors propose thresholds for all sports helmets based on a peak linear acceleration no greater than $90 \mathrm{~g}$ and a peak angular acceleration not exceeding $1700 \mathrm{rad} / \mathrm{sec}^{2}$.

http://thejns.org/doi/abs/10.3171/2014.11.JNS141742

KEY WORDS biomechanics; football; sports helmets; traumatic brain injury; concussion; subdural hematoma; trauma

$\mathrm{F}$ ооотвall helmets were originally introduced in 1896 as protective sports equipment, with devices fashioned out of leather strips. The evolution of leather caps involved the integration of a suspension system, as in the 1930s MacGregor-Goldsmith leather helmet. However, when helmets were introduced, the incidence of head injuries actually increased because of the pervasiveness of head-to-head collisions.

In response to an epidemic of football-related fatalities during the 1939 season, the National Collegiate Athletic Association (NCAA) mandated helmet use at the collegiate football level. The National Football League (NFL) followed suit for professional players in 1943. Football hel- met design evolved significantly around this period, with the development of the first plastic shell helmet in 1937.

After 38 fatalities on the football field in 1969, the National Operating Committee on Standards for Athletic Equipment (NOCSAE) was formed to establish standards for helmet testing. Specifications were revised in 1977 to include procedures for periodic helmet recertification, which were adopted by the NCAA and the National Federation of State High School Associations in 1978, mandating that all players wear helmets that meet NOCSAE test standards.

In the early 1970s, the American Society for Testing Materials (ASTM) formed a committee (F-08) to develop

ABBREVIATIONS AIS = Abbreviated Injury Scale; ASTM = American Society for Testing Materials; GIS = Gadd Severity Index; HITS = Head Impact Telemetry System; NCAA = National Collegiate Athletic Association; NFL = National Football League; NOCSAE = National Operating Committee on Standards for Athletic Equipment. ACCOMPANYING EDITORIAL See pp 665-666. DOI: 10.3171/2014.12.JNS142594.

SUBMITTED July 30, 2014. ACCEPTED November 12, 2014.

INCLUDE WHEN CITING Published online October 16, 2015; DOI: 10.3171/2014.11.JNS141742. 
a test method for shock attenuation in football helmets. ${ }^{2}$ While the ASTM defines pass/fail criteria for football helmets based purely on linear accelerations (currently 275-g threshold), the NOCSAE test method uses the Gadd Severity Index (GSI), ${ }^{7}$ an acceleration-time tolerance profile based on fracture patterns of animal and human cadaveric skulls. The NOCSAE uses a twin wire-guided drop test whereby a helmeted surrogate head, without the neck, is impacted onto an anvil. The pass/fail threshold for football helmets is based on a GSI score of 1200 . None of the current standards for assessing the performance of football helmets, or helmets for any sports application in the US, require measurement of the types of forces believed to be responsible for rotational brain injuries, including concussion and subdural hematoma.

According to data from the National Center for Catastrophic Sports Injury Research, 243 football deaths were recorded between 1990 and 2010 among high school and college football players. ${ }^{3}$ This is equal to an average of 12 deaths each year in the US. Sixty-two of these deaths were attributed to brain injury, typically subdural hematoma. Concussion is considerably more prevalent. In the US it is estimated that 300,000 sports-related concussions occur annually. Among individuals 15-24 years of age, sports are second only to motor vehicle crashes as the leading cause of concussion. Football is reported to have the highest incidence of sports-related concussion, followed by hockey and lacrosse. ${ }^{18}$

\section{Biomechanics of Brain Injury}

Traumatic brain injury is associated with 2 primary mechanisms: impact loading and impulse loading. A direct blow transmitted primarily through the center of mass of the head produces impact loading, which can result in extracranial focal injuries such as contusions, lacerations, and external hematomas, as well as skull fractures. Shock waves from blunt force trauma can also cause underlying focal brain injuries such as cerebral contusions, subarachnoid hematomas, and intracerebral hemorrhages. Sudden movement of the brain relative to the skull induces impulse or inertial loading, which can cause concussion. Inertial loading at the surface of the brain can cause subdural hemorrhage due to bridging vein rupture, whereas its effects on the neural structures deeper within the brain can produce diffuse axonal injury.

Research conducted by Holbourn ${ }^{12}$ first cited angular (rotational) acceleration as the principal mechanism in brain injury. In studies involving live primates and physical models, ${ }^{8-11,29}$ Gennarelli, Thibault, and colleagues investigated the importance of rotational acceleration in brain injury causation, concluding that angular acceleration contributes more than linear acceleration to the generation of concussive injuries, diffuse axonal injuries, and subdural hematomas.

\section{Skull Fracture}

Thresholds for skull fracture are based on experiments involving 25 gel-filled human cadaveric skulls that were exposed to impacts..$^{22}$ Each head was filled with gelatin to accurately represent head mass, and the rubber skin of a Hybrid II mannequin covered the skull. A series of 42 frontal, 36 occipital, and 58 temporal blows were delivered to the suspended cadaveric heads, during which linear accelerations were measured. A skull fracture threshold of $250 \mathrm{~g}$ was determined for frontal and occipital impacts 3 msec in duration, decreasing to $140 \mathrm{~g}$ as the impact duration increased to $7 \mathrm{msec}$. The skull fracture threshold for lateral impacts was reported as $120 \mathrm{~g}$ over $3 \mathrm{msec}$, decreasing to $90 \mathrm{~g}$ as impact duration increased to $7 \mathrm{msec}$. These findings indicated that skull fracture threshold and impact duration are inversely related.

\section{Concussion}

In 1974 Ommaya and Gennarelli investigated the effect of pure translational (linear) or rotational (angular) loading on the heads of primates without inducing contact phenomena. ${ }^{21}$ It was learned that pure translation produces focal injuries, such as contusions, while rotationally induced inertial loading causes diffuse effects, including concussion and subdural hematoma.

Several studies have been performed to identify thresholds for concussion in football. Pellman and colleagues conducted a series of biomechanical studies in which video-recorded concussive impacts during NFL football games were analyzed. ${ }^{23}$ The investigators reported that concussions were related to linear and rotational accelerations on the order of $98 \pm 28 \mathrm{~g}$ and $6432 \pm 1813 \mathrm{rad} / \mathrm{sec}^{2}$, respectively. Results showed that a concussive injury is possible at $45 \mathrm{~g} / 3500 \mathrm{rad} / \mathrm{sec}^{2}$, while $5500 \mathrm{rad} / \mathrm{sec}^{2} \mathrm{repre}-$ sents a $50 \%$ risk of concussive trauma.

Rowson and Duma conducted extensive laboratory and field-based biomechanical evaluations of head injuries in football. ${ }^{24-27}$ Findings were based on a large database of head impacts recorded using the Head Impact Telemetry System (HITS), developed by Simbex Inc., which utilizes an array of uni-axial accelerometers in the crown of a player's helmet. Given data for 62,974 subconcussive impacts and 37 diagnosed concussions, the investigators proposed a concussion threshold of $104 \pm 30 \mathrm{~g}$ and $4726 \pm$ $1931 \mathrm{rad} / \mathrm{sec}^{2} .{ }^{26}$ Their research also offered thresholds for subconcussive impacts, whose cumulative effects, some believe, may be correlated with the early onset of dementia. Average linear and angular accelerations for the upper $50 \%$ of subconcussive impacts in the HITS data set consist of impacts of $38 \pm 20 \mathrm{~g}$ and $1528 \pm 984 \mathrm{rad} / \mathrm{sec}^{2}$, respectively, while the top $25 \%$ of subconcussive impacts consist of impacts with average accelerations of $52 \pm 21 \mathrm{~g}$ and $2036 \pm 1124 \mathrm{rad} / \mathrm{sec}^{2} .{ }^{26}$

\section{Subdural Hematoma}

According to Gennarelli ${ }^{10}$ the most common type of acute subdural hematoma results from tearing of veins that bridge the subdural space as they travel from the brain's surface to the various dural sinuses. The severity of injury associated with bridging vein rupture has led to several studies of mechanical failure properties. ${ }^{5,14,15-17,19}$

Löwenhielm performed mechanical tests on 22 human parasagittal bridging vein samples from 11 persons between the ages of 13 and 87 years with no previous brain injury. ${ }^{15} \mathrm{He}$ hypothesized that when the head is exposed to blunt trauma, the brain is displaced with respect to the 
dura, causing bridging veins and surrounding connective tissue to be stretched. Löwenhielm stated that maximal shear stresses occur about $7 \mathrm{msec}$ after impact, coinciding with bridging vein disruption. He concluded that bridging vein ruptures occur if the maximal angular acceleration exceeds $4500 \mathrm{rad} / \mathrm{sec}^{2}$.

Depreitere applied a methodology in which 10 unembalmed cadavers were subjected to 18 occipital impacts of varying magnitudes and durations, producing head rotation in the sagittal plane. ${ }^{5}$ Bridging vein ruptures were detected on autopsy following the injection of contrast dye into the superior sagittal sinus under fluoroscopy. Bridging vein ruptures were produced in 6 impact tests, suggesting a tolerance level of approximately $8000 \mathrm{rad} / \mathrm{sec}^{2}$ for impact durations shorter than $10 \mathrm{msec}$, which seemed to decrease for longer impact durations. Bridging vein failure data from Depreitere and Löwenhielm are presented in Fig. 1. A line of best fit, which is the curve or mathematical function that has the best fit through all of the data points, was computed, along with the $95 \%$ confidence intervals.

Helmets decrease peak force by extending the duration over which the impact is experienced. In the case of football helmets, the typical impact duration is approximately $15 \mathrm{msec}$. This suggests that bridging vein rupture may result with peak angular accelerations on the order of 6000 $\mathrm{rad} / \mathrm{sec}^{2}$, but may be as low as $4000 \mathrm{rad} / \mathrm{sec}^{2}$ after adjusting for the standard error of the mean in this limited data set (Fig. 1).

Depreitere's bridging vein rupture threshold is in agreement with epidemiological evidence presented by Forbes et al., ${ }^{6}$ who reported an appreciable risk of subdural hematoma associated with head impacts resulting in angular accelerations of $5000 \mathrm{rad} / \mathrm{sec}^{2}$. Furthermore, Forbes and colleagues recently documented a $238 \%$ increase in catastrophic head injuries, such as subdural hematomas, particularly among players 18 years old and younger.

In 1985, Ommaya compiled a review of the biomechanics of head injury, ${ }^{20}$ and his results are included in our summary of biomechanical head and brain injury data in Table 1.

It is interesting to note that thresholds for concussive impacts, as calculated by Pellman et al. ${ }^{23}$ and Rowson and Duma, ${ }^{26}$ exceed scientific consensus on thresholds for subdural hematoma in football impacts. If such were correct, then the epidemiological data would reflect an epidemic of subdural hematomas, which is not the case. Therefore, one questions the validity of these studies.

\section{Methods}

The standard NOCSAE testing system involves a headform, which is rigidly affixed to a metal flyarm. The orientation of the headform can be varied to represent frontal, occipital, lateral, and crown impacts. The flyarm is suspended between 2 parallel wires, which guide the fall of the headform onto an anvil. Since the headform is rigidly affixed to the flyarm without a flexible neck, rotational acceleration is prohibited and thus prevents the objective measurement of concussive risk.

Our modified drop test system incorporates measures

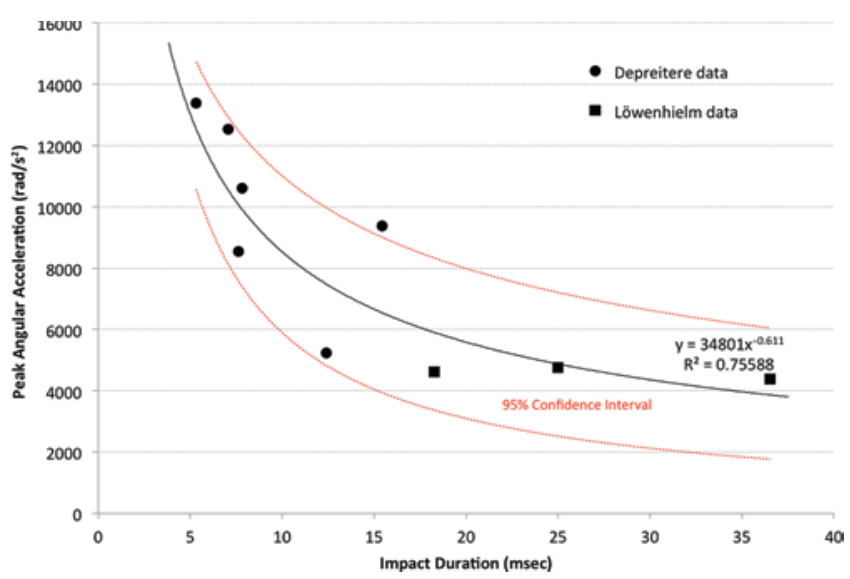

FIG. 1. Bridging vein failure as a function of peak angular acceleration and impact duration (with a line of best fit and $95 \%$ confidence intervals). Figure is available in color online only.

of both linear and angular accelerations (Fig. 2). A modification to the NOCSAE standard test apparatus was developed and validated for impact testing of protective headwear. ${ }^{4}$ This apparatus incorporates a 50th percentile Hybrid III head and neck assembly from Humanetics ATD. The flexible neck is affixed between the head and flyarm. All other parameters are unchanged. When the headform strikes the anvil, rotational acceleration is unimpeded, thereby permitting measurement of both linear and angular head kinematics in response to the impact.

\section{Instrumentation}

A triaxial accelerometer (PCB Piezotronics Inc.) and 3 ARS PRO-18K angular rate sensors (Diversified Technical Systems Inc.) affixed to a triaxial block were installed at the center of mass of the Hybrid III headform (Humanetics ATD). Data from the accelerometer and angular rate sensors were acquired using National Instruments compactDAQ hardware.

Twenty-one football helmet models were evaluated (Table 2). Several models are no longer current, and 5 of these retired models were not available in new condition. Most of the helmets were new, and 3 youth models were included. Except for the MacGregor-Goldsmith leatherhead, of which we had only 1 sample, 3 samples of each helmet were evaluated. Each helmet was impacted 5 times in the occipital area from a drop height $2.0 \mathrm{~m}$ onto a flat steel anvil, in accordance with ASTM standards., ${ }^{1,2}$ An impact velocity of $6.2 \mathrm{~m} / \mathrm{sec}(13.9 \mathrm{mph})$ was computationally verified. Calibration routines were performed at the start and the end of data collection by dropping the Hybrid III headform onto a modular elastomer programmer (MEP) pad 1-in thick with durometer 60 (A scale). An SEM of 0.061 was computed between the pre- and post-calibration tests, indicating high repeatability of the tests.

\section{Analysis}

In accordance with SAE J211/1,28 data from the ana$\log$ sensors were acquired at $10,000 \mathrm{~Hz}$ per channel using LabVIEW (National Instruments) and then filtered in MATLAB (MathWorks) using a phaseless eighth-order 
TABLE 1. Summary of biomechanical head and brain injury thresholds

\begin{tabular}{|c|c|c|c|c|}
\hline Injury & Source & Description & Linear Acceleration (g) & Angular Acceleration (rad/sec $\left.{ }^{2}\right)$ \\
\hline \multirow[t]{4}{*}{ Skull fracture } & \multirow[t]{4}{*}{ Ono, 1998} & 3 msec-frontal/occipital & 250 & \\
\hline & & 3 msec-temporal & 120 & \\
\hline & & $7 \mathrm{msec}$-frontal/occipital & 140 & \\
\hline & & 7 msec-temporal & 90 & \\
\hline \multirow[t]{4}{*}{ Subconcussive impact } & Ommaya, 1985 & AIS Score 2: moderate & & $\leq 1700$ \\
\hline & Pellman et al., 2003 & Average from NFL data set & $57 \pm 22$ & $4029 \pm 1438$ \\
\hline & \multirow[t]{2}{*}{ Rowson \& Duma, 2013} & Top 50\% & $38 \pm 20$ & $1528 \pm 984$ \\
\hline & & Top 25\% & $52 \pm 21$ & $2036 \pm 1124$ \\
\hline \multirow[t]{6}{*}{ Concussion } & \multirow[t]{2}{*}{ Ommaya, 1985} & AIS Score 3: serious & & $\leq 3000$ \\
\hline & & AIS Score 4: severe & & $\leq 3900$ \\
\hline & \multirow[t]{3}{*}{ Pellman et al., 2003} & Average from NFL data & $98 \pm 28$ & $6432 \pm 1813$ \\
\hline & & Lowest concussion in NFL & 45 & 3500 \\
\hline & & $50 \%$ risk of concussion & & 5500 \\
\hline & Rowson \& Duma, 2013 & Average collegiate data & $104 \pm 30$ & $4726 \pm 1931$ \\
\hline \multirow[t]{4}{*}{ Subdural hematoma } & Löwenhielm, 1974 & & & 4500 \\
\hline & Ommaya, 1985 & AIS Score 5: critical & & $\leq 4500$ \\
\hline & Depreitere et al., 2006 & Calculated for football helmet impact & & $4000-6000$ \\
\hline & Forbes et al., 2014 & Epidemiological evidence & & 5000 \\
\hline
\end{tabular}

Butterworth filter. Cutoff frequencies of 1650 and $500 \mathrm{~Hz}$ were used for the linear accelerometers and angular rate sensors, respectively. Angular acceleration measures were derived from the angular velocity data based on a 5-point least-squares quartic equation. Impact durations were determined based on linear acceleration data.

\section{Results}

Table 3 presents a summary of results averaged across 5 tests and 3 samples for each of the 21 helmet models tested. Most helmets met the 140-g skull fracture threshold based on Ono. ${ }^{22}$ Performance ranged from 94 to 225 $\mathrm{g}$, with an average of $125 \mathrm{~g}$. The Schutt Vengeance ranked first among helmets tested for ability to mitigate linear accelerations. However, the retired Adams a2000 Pro and Schutt Air Advantage helmets, as well as the current Raw-

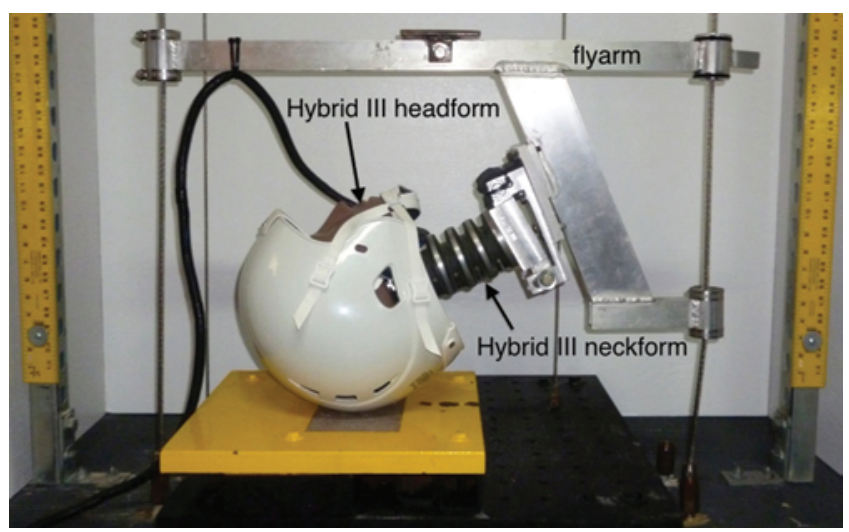

FIG. 2. Modified head drop system with Hybrid III head and neck assembly. Figure is available in color online only. lings Quantum and Schutt Air XP helmets, failed to meet this threshold based on an impact velocity of $6.2 \mathrm{~m} / \mathrm{sec}$.

In terms of angular (rotational) acceleration, helmet performance ranged from 2628 to $4665 \mathrm{rad} / \mathrm{sec}^{2}$, with an

TABLE 2. Football helmets tested

\begin{tabular}{|c|}
\hline 1930s MacGregor-Goldsmith Leatherhead* $\dagger$ \\
\hline Adams a2000 Pro* $†$ \\
\hline Rawlings Impulse \\
\hline Rawlings Quantum \\
\hline Rawlings Quantum Plus \\
\hline Riddell Little Pro*†‡ \\
\hline Riddell VSR4*† \\
\hline Riddell Revolution \\
\hline Riddell Revolution Speed \\
\hline Riddell 360 \\
\hline SG Adult Varsity \\
\hline Schutt Air Advantage* $\dagger$ \\
\hline Schutt lon 4D* \\
\hline Schutt DNA Pro+ \\
\hline Schutt DNA Pro+ youth $\ddagger$ \\
\hline Schutt Air XP \\
\hline Schutt Air XP Pro \\
\hline Schutt Vengeance DCT \\
\hline Xenith X1 adult* \\
\hline Xenith $\mathrm{X} 1$ youth* $\ddagger$ \\
\hline Xenith X2 adult \\
\hline
\end{tabular}

\footnotetext{
* No longer current.

$\uparrow$ Not available in new condition.

$\ddagger$ Youth model.
} 
TABLE 3. Summary of results

\begin{tabular}{|c|c|c|c|c|c|}
\hline Helmet & $\begin{array}{c}\text { Linear } \\
\text { Acceleration (g) }\end{array}$ & GSI & $\begin{array}{l}\text { Angular Velocity } \\
\text { (rad/sec) }\end{array}$ & $\begin{array}{c}\text { Angular } \\
\text { Acceleration }\left(\mathrm{rad} / \mathrm{sec}^{2}\right)\end{array}$ & $\begin{array}{l}\text { Impact Duration } \\
\text { (msec) }\end{array}$ \\
\hline None & 1039.1 & $16,639.7$ & 14.9 & 9203.5 & 2.1 \\
\hline Adams a2000 Pro* $†$ & 154.1 & 1051.9 & 38.0 & 3754.4 & 13.1 \\
\hline Rawlings Impulse & 111.4 & 637.5 & 33.2 & 3532.4 & 14.5 \\
\hline Rawlings Quantum & 141.1 & 888.3 & 25.0 & 2909.8 & 13.3 \\
\hline Rawlings Quantum Plus & 102.6 & 590.9 & 22.6 & 3290.9 & 15.7 \\
\hline Riddell Little Pro*†‡ & 133.4 & 759.6 & 40.8 & 4348.9 & 14.0 \\
\hline Riddell VSR4 ${ }^{*} \dagger$ & 119.0 & 700.4 & 31.6 & 3973.8 & 13.2 \\
\hline Riddell Revolution & 128.3 & 794.1 & 28.4 & 3661.2 & 12.8 \\
\hline Riddell Revolution Speed & 133.8 & 765.6 & 26.8 & 3419.2 & 13.9 \\
\hline Riddell 360 & 131.0 & 726.5 & 23.0 & 3623.1 & 13.2 \\
\hline Schutt Air Advantage* $\dagger$ & 144.9 & 913.7 & 35.6 & 3561.9 & 14.2 \\
\hline Schutt lon 4D* & 96.0 & 462.0 & 11.1 & 4665.1 & 16.6 \\
\hline Schutt DNA Pro+ & 100.5 & 529.7 & 33.4 & 3113.2 & 20.0 \\
\hline Schutt DNA Pro+ youth $\ddagger$ & 134.9 & 745.0 & 32.2 & 3651.2 & 11.3 \\
\hline Schutt Air XP & 150.3 & 918.3 & 27.8 & 3297.0 & 12.3 \\
\hline Schutt Air XP Pro & 98.2 & 524.0 & 29.8 & 3131.5 & 21.6 \\
\hline Schutt Vengeance DCT & 93.7 & 486.5 & 25.4 & 3002.2 & 16.8 \\
\hline SG Adult Varsity & 103.9 & 537.2 & 28.2 & 3511.0 & 17.6 \\
\hline Xenith $\mathrm{X} 1$ adult* & 105.1 & 599.5 & 34.0 & 3834.4 & 15.4 \\
\hline Xenith $\mathrm{X} 1$ youth $^{*} \ddagger$ & 95.5 & 541.0 & 33.2 & 3788.9 & 18.2 \\
\hline Xenith $\mathrm{X} 2$ adult & 119.6 & 710.3 & 34.5 & 4199.9 & 15.6 \\
\hline 1930s MacGregor-Goldsmith leatherhead ${ }^{*} \dagger$ & 225.5 & 1087.6 & 25.9 & 2628.2 & 8.2 \\
\hline
\end{tabular}

* No longer current.

$\dagger$ Not available in new condition.

$\ddagger$ Youth model.

average of $2343 \mathrm{rad} / \mathrm{sec}^{2}$. Of the current varsity helmets, the Rawlings Quantum ranked first in terms of mitigating angular (rotational) accelerations.

Figure 3 presents peak angular acceleration versus impact duration for current and retired varsity football helmets. Results for 1 retired football helmet and 3 current varsity helmets-Schutt Ion 4D, Xenith X2, SG Adult Varsity, and Schutt DNA Pro+-fall within the lower confidence level, indicating the possibility of subdural hematoma arising from an impact of $6.2 \mathrm{~m} / \mathrm{sec}$. Interestingly, the helmet that seemingly offers the best possible protection against subdural hematoma is the 1930s MacGregorGoldsmith leatherhead.

Given concussion thresholds according to Ommaya, ${ }^{20}$ Pellman et al., ${ }^{23}$ and Rowson and Duma,${ }^{26}$ all current varsity football helmets ought to provide adequate protection against the risk of concussion (Fig. 4). However, epidemiological evidence of $300,000+$ sports-related concussions in the US annually suggests otherwise..$^{18}$

Considering only those varsity helmets currently on the market, we are left with 12 models representing Rawlings, Riddell, Schutt, SG, and Xenith. The Schutt Vengeance offers the best protection against linear accelerations (that is, forces that induce focal head injuries, such as skull fracture), while the Rawlings Quantum offers the best protection against angular (rotational) accelerations (that is, forces that cause concussions and subdural hematomas).

Skull fracture risk was determined for each of the 12 current varsity football helmets by calculating the percent reduction in linear acceleration relative to a 140-g skull fracture threshold, according to Ono..$^{22}$ Risk of subdural hematoma was determined by calculating the percent

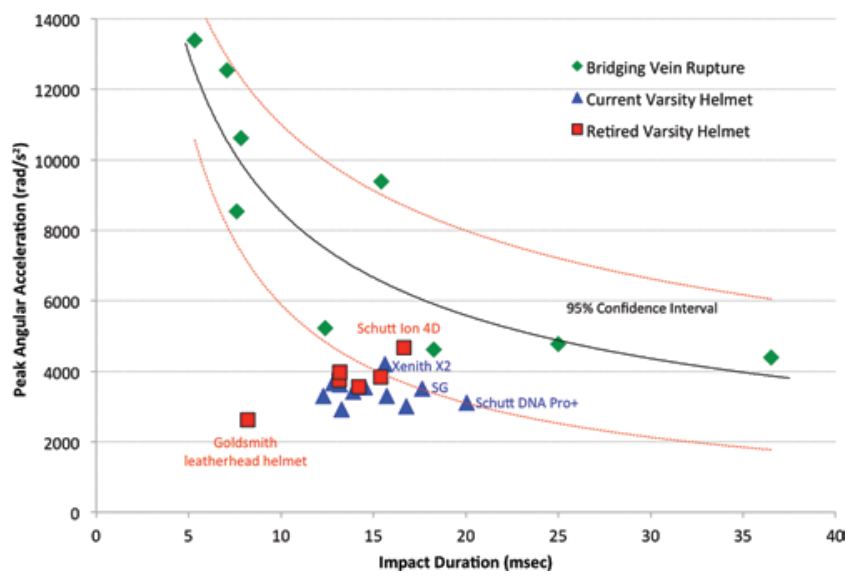

FIG. 3. Protection against subdural hematoma by current and retired varsity football helmets. Figure is available in color online only. 


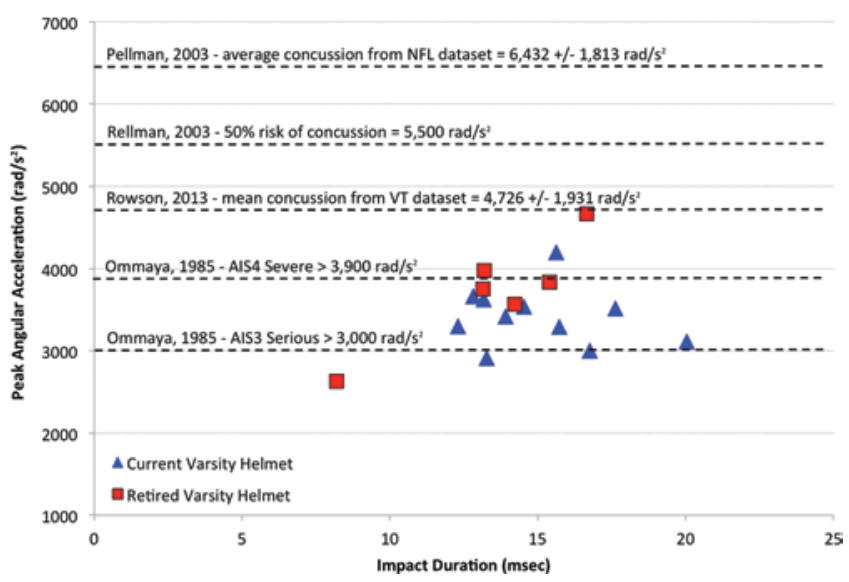

FIG. 4. Protection against concussion by current and retired football helmets. Figure is available in color online only.

reduction in angular acceleration relative to the bridging vein failure threshold computed as a function of impact duration (Fig. 1). Concussion risk was determined by calculating the percent reduction in angular acceleration relative to a 3000-rad/ $/ \mathrm{sec}^{2}$ threshold, according to Ommaya. ${ }^{20}$

Ranking the helmets according to their performance under these criteria, we determined that the Schutt Vengeance performed the best overall. The ranked summary of results for current varsity football helmets is presented in Fig. 5.

\section{Discussion}

Current sports helmet standards fail to address the risks of brain injuries, including concussions and subdural hematomas. The National Operating Committee on Standards for Athletic Equipment (NOCSAE) recently stated, "there is no scientific agreement at all on what the threshold for concussion is." We believe this confusion is attributable to the inadequacy of several previous studies that have sought to offer concussion thresholds.

In 1985, building upon the research by Löwenhielm,,${ }^{15-17}$ Ommaya published data on brain injury risk, classified according to the Abbreviated Injury Scale (AIS), as a function of rotational (angular) accelerations. ${ }^{20} \mathrm{He}$ proposed that critical (AIS Score 5) brain injury can be caused by angular accelerations $\geq 4500 \mathrm{rad} / \mathrm{sec}^{2}$, while moderate (AIS Score 2) brain injury can result from angular accelerations $>1700 \mathrm{rad} / \mathrm{sec}^{2}$. Furthermore, Forbes et al. reported that the risk of subdural hematoma becomes appreciable with rotational accelerations of $5000 \mathrm{rad} / \mathrm{sec}^{2}{ }^{6}{ }^{4}$ contrast, an NFL data set suggested that concussions are associated with angular accelerations of approximately $6432 \pm 1813$ $\mathrm{rad} / \mathrm{sec}^{2}$, and Duma and Rowson suggested a threshold of $4726 \pm 1931 \mathrm{rad} / \mathrm{sec}^{2}$ based on their study of concussion in collegiate athletes. ${ }^{23,26}$

The Pellman ${ }^{23}$ and Rowson ${ }^{26}$ studies may be flawed, as their data suggest that limits for concussion are actually higher than those for subdural hematomas, which directly opposes epidemiological evidence. ${ }^{3,18}$ Further, the validity of the HITS instrumentation, which Rowson and Duma used exclusively in their field testing, has been seriously questioned. Jadischke and colleagues demonstrated that the majority of recordings using this system have an absolute error greater than $15 \%$ and that the root mean square error for peak linear acceleration was $59.1 \% .^{13}$ Moreover, the sampling rate of the HITS technology is limited to $1000 \mathrm{~Hz}$, which fails to meet the SAE J211 ${ }^{28}$ guidance for

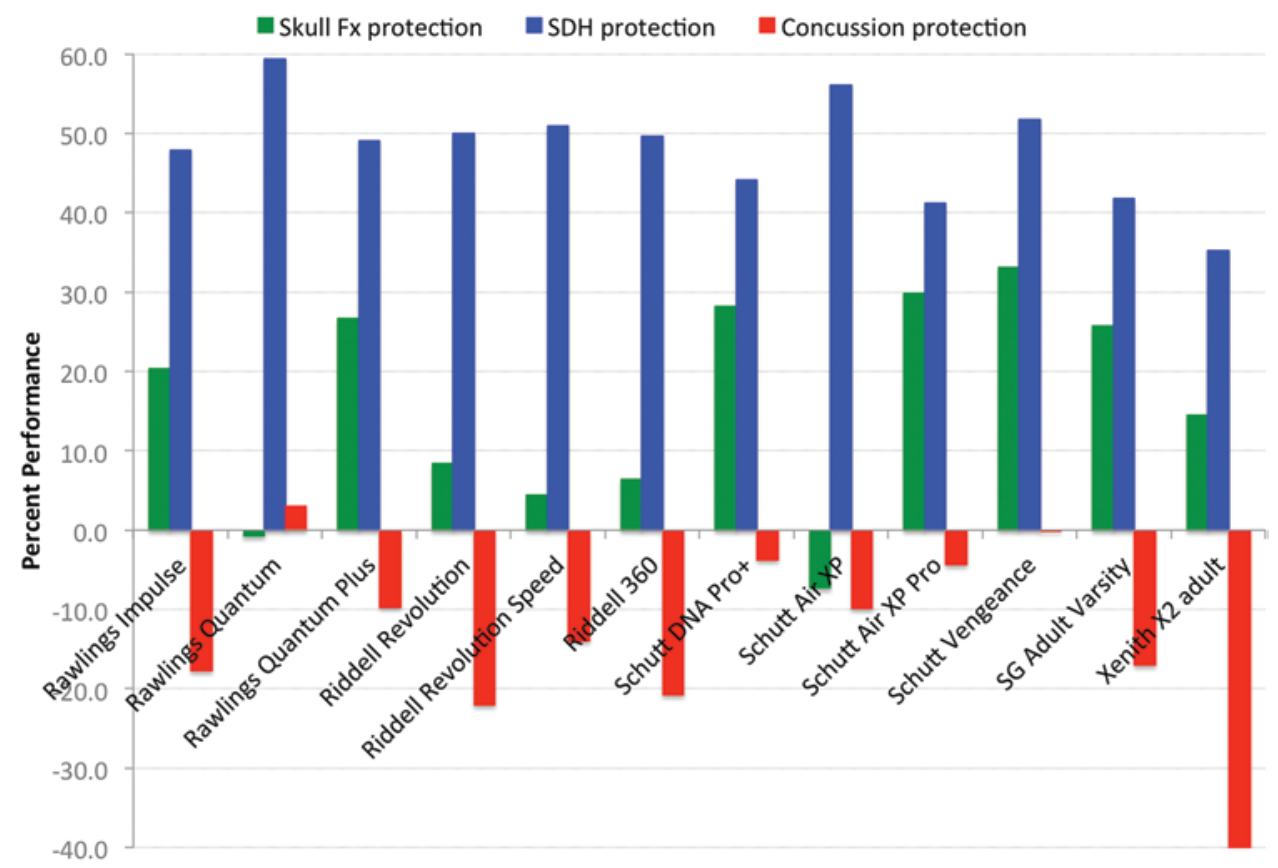

FIG. 5. Summary of results for current varsity football helmets (in rank order). Fx = fracture; SDH = subdural hematoma. Figure is available in color online only. 
impact measurement. Typical impact duration is on the order of 11-15 msec; therefore, any impact would be grossly under-sampled (that is, there are too few measures). Hence, any proposed thresholds based on this system may by suspect.

We propose helmet protection thresholds to reduce the risk of head and brain injuries in contact sports. Specifically, we recommend that sports helmets be assessed according to the following criteria: 1) To minimize the risk of skull fractures, given research published by Ono, ${ }^{22}$ we propose a threshold of $140 \mathrm{~g}$ for peak linear acceleration to the frontal and occipital areas of the head and $90 \mathrm{~g}$ for peak linear acceleration for lateral impacts. 2) To minimize the risk of subdural hematoma, we propose that peak angular accelerations not exceed $50 \%$ of the bridging vein failure threshold, calculated as a function of impact duration. ${ }^{5}$ For example, the average impact duration measured across 12 current varsity football helmets in the present study was $15.2 \mathrm{msec}$. A bridging vein failure threshold of $4000 \mathrm{rad} / \mathrm{sec}^{2}$ was thus computed based on the equation of the lower confidence interval of the regression line presented in Fig. 1. Allowing for tolerance for intrinsic personal factors that might elevate individual susceptibility, we suggest a peak angular acceleration no greater than $50 \%$ of the computed bridging vein failure threshold. 3) To minimize the risk of concussion, we propose a peak angular acceleration threshold of $3000 \mathrm{rad} / \mathrm{sec}^{2}$. 4) To minimize the potential cumulative risk of subconcussive impacts, we propose a peak angular acceleration threshold of $1700 \mathrm{rad} / \mathrm{sec}^{2}$, based on Ommaya's suggested threshold for moderate brain injury. ${ }^{20}$ In the interest of simplification and to maximize protection against head and brain injuries to football players and other sports participants of all ages, these thresholds can be summarized as a peak linear acceleration no greater than $90 \mathrm{~g}$ and a peak angular acceleration not exceeding $1700 \mathrm{rad} / \mathrm{sec}^{2}$. These proposed thresholds may be refined through future studies.

Pellman ${ }^{23}$ reported that concussed players experienced head impacts of $9.3 \pm 1.9 \mathrm{~m} / \mathrm{sec}(20.8 \pm 4.2 \mathrm{mph})$, which is considerably greater than the impact velocity against which helmets were tested in the present study. We, therefore, propose that helmet-testing standards ought to be revised to reflect impact velocities associated with concussive events.

\section{Conclusions}

Our findings demonstrated that not all football helmets provide equal or adequate protection against either focal head injuries or traumatic brain injuries. In fact, some of the most popular helmets on the field ranked among the worst. While protection is improving, none of the current or retired varsity football helmets tested could provide absolute protection against brain injuries, including concussions and subdural hematomas.

It is paramount that protection against traumatic brain injuries be the highest priority. Recent literature suggests that even a single mild traumatic brain injury can have devastating neurological consequences and that players who experience more than 1 mild brain injury are retiring from the game for the sake of their long-term health.
To maximize protection against head and brain injuries to football players and other sports participants of all ages, we propose basing thresholds for all sports helmets on a peak linear acceleration no greater than $90 \mathrm{~g}$ and a peak angular acceleration not exceeding $1700 \mathrm{rad} / \mathrm{sec}^{2}$.

\section{References}

1. ASTM International: F1446-11a: Standard Test Methods for Equipment and Procedures Used in Evaluating the Performance Characteristics of Protective Headgear. West Conshohocken, PA: ASTM International, 2011

2. ASTM International: F429-10: Standard Test Method for Shock-Attenuation Characteristics of Protective Headgear for Football. West Conshohocken, PA: ASTM International, 2007

3. Boden BP, Breit I, Beachler JA, Williams A, Mueller FO: Fatalities in high school and college football players. Am J Sports Med 41:1108-1116, 2013

4. Caccese V, Ferguson J, Lloyd J, Edgecomb M, Seidi M, Hajiaghamemar M: Response of an impact test apparatus for fall protective headgear testing using a Hybrid-III head/neck assembly. Exp Tech [epub ahead of print], 2014

5. Depreitere B, Van Lierde C, Sloten JV, Van Audekercke R, Van der Perre G, Plets C, et al: Mechanics of acute subdural hematomas resulting from bridging vein rupture. J Neurosurg 104:950-956, 2006

6. Forbes JA, Zuckerman S, Abla AA, Mocco J, Bode K, Eads $\mathrm{T}$ : Biomechanics of subdural hemorrhage in American football: review of the literature in response to rise in incidence. Childs Nerv Syst 30:197-203, 2014

7. Gadd C: Use of a Weighted-Impulse Criterion for Estimating Injury Hazard. SAE Technical Paper 660793. Warrendale, PA: SAE International, 1966

8. Gennarelli TA, Adams JH, Graham DI: Acceleration induced head injury in the monkey. I. The model, its mechanical and physiological correlates. Acta Neuropathol Suppl 7:23-25, 1981

9. Gennarelli TA, Ommaya AK, Thibault LE: Comparison of translational and rotational head motions in experimental cerebral concussion. Stapp Car Crash J 15:797-803, 1971

10. Gennarelli TA, Thibault LE: Biomechanics of acute subdural hematoma. J Trauma 22:680-686, 1982

11. Gennarelli TA, Thibault LE, Adams JH, Graham DI, Thompson CJ, Marcincin RP: Diffuse axonal injury and traumatic coma in the primate. Ann Neurol 12:564-574, 1982

12. Holbourn AHS: Mechanics of head injuries. Lancet 242:438-441, 1943

13. Jadischke R, Viano DC, Dau N, King AI, McCarthy J: On the accuracy of the Head Impact Telemetry (HIT) system used in football helmets. J Biomech 46:2310-2315, 2013

14. Lee MC, Haut RC: Insensitivity of tensile failure properties of human bridging veins to strain rate: implications in biomechanics of subdural hematoma. J Biomech 22:537-542, 1989

15. Löwenhielm P: Dynamic properties of the parasagittal bridging veins. Z Rechtsmed 74:55-62, 1974

16. Löwenhielm P: Strain tolerance of the vv. cerebri sup. (bridging veins) calculated from head-on collision tests with cadavers. Z Rechtsmed 75:131-144, 1974

17. Löwenhielm P: Tolerance level for bridging vein disruption calculated with a mathematical model. J Bioeng 2:501-507, 1978

18. Marar M, McIlvain NM, Fields SK, Comstock RD: Epidemiology of concussions among United States high school athletes in 20 sports. Am J Sports Med 40:747-755, 2012

19. Meaney DF: Biomechanics of Acute Subdural Hematoma in the Subhuman Primate and Man [dissertation]. Philadelphia: University of Pennsylvania, 1991

20. Ommaya A: Biomechanics of head injury-experimental 
aspects, in Nahum AM, Melvin JW (eds): The Biomechanics of Trauma. Norwalk, CT: Appleton-Century-Crofts, 1985, pp 245-269

21. Ommaya AK, Gennarelli TA: Cerebral concussion and traumatic unconsciousness. Correlation of experimental and clinical observations of blunt head injuries. Brain 97:633-654, 1974

22. Ono K: Current status on human head impact tolerance, in Yoganandan N, Pintar FA, Larson SJ, Sances A Jr (ed): Frontiers in Head and Neck Trauma: Clinical and Biomechanical. Amsterdam: IOS Press, 1998, pp 183-199

23. Pellman EJ, Viano DC, Tucker AM, Casson IR, Waeckerle JF: Concussion in professional football: reconstruction of game impacts and injuries. Neurosurgery 53:799-814, 2003

24. Rowson S, Brolinson G, Goforth M, Dietter D, Duma S: Linear and angular head acceleration measurements in collegiate football. J Biomech Eng 131:061016, 2009

25. Rowson S, Duma SM, Beckwith JG, Chu JJ, Greenwald RM, Crisco JJ, et al: Rotational head kinematics in football impacts: an injury risk function for concussion. Ann Biomed Eng 40:1-13, 2012

26. Rowson S, Duma SM: Brain injury prediction: assessing the combined probability of concussion using linear and rotational head acceleration. Ann Biomed Eng 41:873-882, 2013

27. Rowson S, Goforth MW, Dietter D, Brolinson PG, Duma SM: Correlating cumulative sub-concussive head impacts in football with player performance - biomed 2009. Biomed Sci Instrum 45:113-118, 2009
28. SAE International: J211/1: Instrumentation for Impact Test - Part 1-Electronic Instrumentation. Warrendale, PA: SAE International, 2007

29. Thibault LE, Gennarelli TA: Biomechanics of diffuse brain injuries. Presented at the 29th Stapp Car Crash Conference, Washington DC, 1985 (Abstract) (http://papers.sae. org/856022/) [Accessed May 15, 2015]

\section{Disclosure}

Dr. Conidi is a consultant for the NFL, NHL, NFL Concussion Lawsuit, and MLB. This study was funded by BRAINS Inc., with additional contributions from the Seeing Stars Foundation.

\section{Author Contributions}

Conception and design: both authors. Acquisition of data: Lloyd. Analysis and interpretation of data: both authors. Drafting the article: both authors. Critically revising the article: both authors. Reviewed submitted version of manuscript: both authors. Approved the final version of the manuscript on behalf of both authors: Lloyd.

\section{Correspondence}

John Lloyd, BRAINS, Inc., 32824 Michigan Ave., San Antonio, FL 33576. email: john@drbiomechanics.com. 